\title{
The Study of Human Resource Support Force under the Background of Regional Industry Structure Upgrading
}

\author{
Ping Dong \\ Shandong Yingcai University, Ji'nan, 250014, China
}

\begin{abstract}
Keywords: Industry structure. Adjustment. Talent demand
\end{abstract}
\begin{abstract}
As China`s industry structure adjustment upgrading enter into a critical stage,the talent demand problem is yet to handle. The high-tech talent is has great influence in the industry development optimizing and upgrading, meanwhile, the adjustment and upgrading of the industry structure has put forward higher standard for the talents needed both in quantity and quality, this paper starts from the relation between the upgrading and adjustment of regional industry and the senior talents, combined with the regional industry structure upgrading trend, it analyzed the talents demands changes situation and how to solve the talent demand problem.
\end{abstract}

\section{Introduction}

For the economic development of a country, the industry is of significant importance, to narrow it down to the regional economy development, the regional industry also play the leading role, the past economic practice has shown that the regional industry structure adjustment is upgrading, it is not only the driving force of the regional economic development, but also an important part of the economy comprehensive competitiveness of this region. Currently, China is in the critical stage of industry structure adjustment and economy growth mold transformation, while this would inevitably change the talent demand in the past industry, this change is reflected in a fact that high-tech talent has put forward higher standard from both the quantity and quality, so by the analysis of China`s regional structure adjustment trend and the changing situation of the talent demand under such background, draw up corresponding talent cultivation plan according to the educational development rules and talent growing rules, in order to satisfy the growing needs for talent demand, this research is of significant importance to the current economic development.

\section{The current situation of China`s regional industry structure changes}

China`s economy zone is divided into three major parts, which are the eastern, central and western respectively, the natural resource,the regional location,the economic development level in the three major zones are vastly different, so the education resource distribution are also different, the talent supply situation is also very different. Meanwhile, China now is in a critical stage of regional industry structure upgrading and adjustment, the three major zone economy industry structure`s changes will lead to the changes of distribution in the human resource demand, which can be shown in the type, level,number and many other aspects, meanwhile the talent supply can effect the regional industry structure upgrading greatly to some extent, so if we want to change our growth mode from the traditional resource-consumption and environment-pollution type to the technology and innovation-driven type, adjust the regional industry structure, it is necessary to pay attention to the cultivation and introduction of the talent. Although the three major regional economy development zone have very different development level, but they all face the same talent-demand problems in the industry structure upgrading and adjustment process.

According to this current regional economy development theory, the measurement of region`s economy development level usually is the industry structure of this region, and divide the economy development level into different stage according to this standard, there are some scholar even consider the regional industry structure upgrading and adjustment as an important indicator in investigating the regional economy. The regional economy structure changes means that the labor force will transfer between the three major industry, while this transfer means the labor force 
indicates the state and average individual income of this region's development, usually, with the rising of the development of this region`s development and average individual income, the transfer of the labor force in this three major industry should be from the first industry to the second industry, then to the third industry.According to the distribution of labor force in this three major industry, the first industry in losing its weighing, while the third industry`s proportion id going higher, so with the adjustment of the region economy industry structure, the distribution of the talent should also follow this rule.

\section{China`s regional industry structure adjustment`s requirements and demand}

In the past, people usually held the opinion that the industry structure will decide the talent demand structure, but the latest research result has shown that this opinion is completely wrong, the industry structure and talent demand structure is not a uni-directional relationship, on the contrary, they are in a interactive relationship, they are inter-dependent. Indeed,in the past, the talent demand of a local economy, its location,type, specification and even the quantity and quality all greatly effected by the local industry structure, but as the regional industry structure upgrades and adjust, weather it has sufficient human resource will decide its local industry structure upgrading and adjustment process, their mutual- restriction relationship is reflected in the following aspects: the first is "talent structure is restricted by the industry structure" , the talent structure adjustment must proceed according to the industry structure upgrading, thus it can truly promise that the students graduated from school can serve and develop the upgraded industry; secondly, "there must be matched talent structure for the industry structure optimizing and upgrading” . According to the human resource theory "push and pull of the flow" ,the talent structure and industry structure seek the balance point in the continuous push and pull process.The optimizing and upgrading of all the regional industry structure are sure to have a higher demand for the talent, at the same time,expand the regional talent input rationally will sure to push the upgrading of the regional industry structure, on the contrary, if the regional talent is not enough, the talent quality is not high enough, it will lead to the regional industry structure upgrading to slow down.

As China`s regional industry structure constantly adjust or upgrade itself, the traditional industry faces the reform and upgrading, a lot of newly-emerged industry start to grow and produce, these all need the support of advanced modern technology, while having senior talent who acquired high-technology now has become the top priority in the talent demand. China`s regional industry upgrading and adjustment will bound to have higher and greater needs for the talent, this new needs and requirements mainly reflected in the following aspects: First, the talent demand increases significantly in its quantity,let`s take Tangshan as an example,according to the past data, there are about 4 million working population in Tangshan at the end of 2012,but most of them are normal workers, the senior talent who master the technology is only less than $10 \%$, meanwhile, nearly half of the senior technician is over 50 years old, this has shown the senior talent may suffer from the hiatus crisis. This data also suggests that the human resource storage in Tangshan is far from enough compared to the needs for industry structure upgrading and adjustment, and this will even effect the growth of local economy. Tangshan is not a single case.with the rapid development of China`s economy,the demand for high-tech talent is increasing as days goes by. It is estimated that in the future 5 years,as the upgrading and adjustment of regional industry structure moves on the right track, the needs for senior talent will also on the rise.

Secondly, there are some changes in the talent demand structure, currently in China`s technicians group, most of them are junior technicians and intermediate technicians, those with senior technicians title accounts for only small number, but as the industry structure upgrades, there are great demand for senior technicians in the area of modern agriculture,modern industry, modern service industry and high-tech industry. Third, there are higher requirements for the overall equality of the talents, as the rapid development of the modern manufacturing industry, numerous new technology have been put into use, the traditional industry`s technology structure has undergone earthshaking changes, the 
technology system start to become more sophisticated, integrated and information-based, at the same time,the society now has step into a information age, the science technology`s changing rate is faster and faster, the update cycle of the products is getting shorter and shorter, the market competition is more and more fierce, these all make the enterprise pay more attention to the cultivation and introduction of corporation, at the same time,the requirements of the talent is higher and higher, currently,the market everywhere is in great need of technology,compound,opening idea, innovation-oriented talent.

\section{The cultivation path of high-technology talents facing the regional industry structure adjustment}

Currently,there are major defect in China`s talent structure, it cannot adapt to the regional industry structure optimizing and upgrading very well, it mainly manifested as: First, the talent level structure is irrational, mainly manifested as there are a lot of junior technicians and intermediate technicians, but few senior technicians, the technicians are in great needs, this directly restricted the upgrading of the regional industry;secondly,the talent cultivation professional structure setting is irrational, the adjustment and upgrading of the industry structure need a large number of talents with professional knowledge and senior skills,such as the upgrading of the second industry need a lot of new material,new energy technician personnel to provide technical support, but currently there are not enough innovation-oriented personnel; at last,the employment structure is irrational, the high-quality practitioners in the second industry are not enough. The number of the practitioners in the third industry are not enough to satisfy the growing needs,many places in China now has sucked into the labor shortage, the higher vocational education must shoulder the responsibility,cultivate the high-end technician personnel which are suitable to the industry structure adjustment and upgrading, the main measure are as following:

\section{Set up the industry structure upgrading and adjustment, as well as the database of the senior technician personnel demand}

Building the high-quality personnel team involves many factors, such as personnel management system, educational system, salary system, social economy environment etc; meanwhile,the industry structure upgrading and adjustment is also a long and painstaking undertaking, so if we want to make the talent cultivation in coordinated with the needs of industry structure adjustment and upgrading, it is needed to clearly take control of the dynamic information of these two elements, in order to adjust the cultivation plan in time, and build a database on the interaction between the industry structure adjustment upgrading and senior personnel needs, thus to serve this function very well. This database must be operated by professional institution, its major function is to issue the dynamic information and talent scale and structure ,technology talent employment situation and other static information, meanwhile, there are many sub-database under the information database, which is in accordance with the industry structure and technology personnel, to design sub-database with different function, which is easy to search the information, such as take the industry structure as the classification standard, set up database of all the industry, and update the industry situation and the talent needs situation, take the technician personnel as classification standard, set up the database of technology type, compound skills type, knowledge skills type, innovation skills type, and make it easier for talent storage.

\section{Adjust the talent cultivation structure according to the industry structure adjustment}

The talent cultivation should be market-oriented, and goes along with the adjustment and upgrading of the industry structure, the talent structure adjustment should follow the following two direction: first, in the area of industry, due attention must be paid to high-tech, culture and education,tourism and other pillar industry, as well as the newly-emerged industry, cultivate professional talent according to the needs of this industry; secondly, highlight the economy,city development plan requirements, attract, restrain the talent and improve their level. Based on that, the vocational education should conduct sufficient investigation according to the new situation after the regional industry structure adjustment and upgrading, estimate the regional future economy 
development`s requirement for talent, adjust the school course structure setting after drawing a reliable conclusion, target on the employment, strive to reduce the extensive and blind education, set up long-term and short-term majors according to the school condition. The long-term majors mainly face the industry which will suffer from talent shortage in a long time, while the short-term majors mainly face the industry which will suffer from talent shortage in a short time,or the enterprise staff training, the vocational college can also set the core professional course according to the needs of professional position.

\section{Relying on the industry corporation, improve the corporation mechanism between the school and enterprise}

If we want to cultivate the talent right for the needs of the market, it is needed to promote and strengthen the cooperation between the school and enterprise. As the three main bodies in the cooperation--enterprise, school and students. They have a mutual beneficial relationship, the enterprise need the school to cultivate the talent,and provide human resource support, the school need to develop education undertaking and scientific undertaking, the students need to find a job and realize their self-value,these three elements are mutual-supportive and mutual-complementary. So the government should encourage and guide this cooperation in the policy level, guide the college to participate in the technology transformation and the development of the new products, encourage the scientific results come into the R\&D department; economically, the government should assure the sound and orderly development of the major projects by tax relief, loans and other measures. Vocational education must change their education philosophy,by virtus of its own education advantage, create the corporation system actively, and realize the real sense corporation between the school and enterprise and cultivate the right talent for the corporations.

\section{Conclusion}

As China`s economy development and regional industry industry structure upgrading and adjustment goes deeper, the talent issue has become more and more important. How to satisfy the growing needs for talent of the enterprise, this now actually has become an important issue for local government, enterprise and even the school, only by constant search of the development rule of the enterprise and the cultivation rule of the talents, can we understand the nature of the relationship between the talent and industry structure adjustment, only by cultivating the high-quality technology-oriented people, can we adapt to China`s regional industry structure upgrading and adjustment, can we truly realize the fast and sound development of the economy.

\section{Acknowledgments}

This paper is Shandong education science "the twelfth five-year plan" project(key) subject+ Shandong regional economy industry structure adjustment and vocational education development mode transformation vertical study; subject No:2013GZ051; Shandong Yingcai college key subjects+ yellow river delta ecological economy zone talent ecological system study; subject number: 13YCZDRW08

\section{References}

[1] Hou Yanwen, Dong Guoli, the Thinking of Tangshan`s Industry Structure Adjustment and Optimizing on the Sustainable Development [J], Group Economy research.

[2] Wang Kaiming, Wan Junkang, Human Resource`s effect to the industry structure[J] Wuhan Science and Technology University Journal(Information and management engineering edition), 2000(026).

[3] Zhou Pin On industry structure adjustment upgrading and the development of the human resource under the background of knowledge economy.[J] Sichuan Normal University Journal(Philosophy and Social Sciences Edition),1999(24) 